J. Clin. Chem. Clin. Biochem.

Vol. 26, 1988, pp. $447-451$

(C) 1988 Waiter de Gruyter \& Co.

Berlin - New York

\title{
Determination of Platelet Monoamine Oxidase by New Continuous Spectrophotometric Method
}

\author{
By I. D. Ivanovic \\ Central Clinical-Chemical Laboratory Military Medical Academy, Belgrade and \\ Nada Majkić-Singh \\ Department of Biochemistry, Faculty of Pharmacy, Belgrade, Yugoslavia
}

(Received September 17, 1987/February 1, 1988)

Summary: A simple, continuous spectrophotometric method for the determination of tissue monoamine oxidase based on the oxidation of 2,2'-azino-di-(3-ethylbenzthiazoline-6-sulphonate) (ABTS) using peroxidase has already been described (Ivanović, I. \& Majkić-Singh, N. (1986) Fresenius Z. Anal. Chem. 324, 307). In the present study the method is optimised for platelet monoamine oxidase assay and applied to healthy persons and schizophrenic patients. The obtained data were statistically analysed. The continuous ABTS method is sensitive, precise ( $\mathrm{CV}$ below $6.9 \%)$ and linear up to $83 \mathrm{U} / \mathrm{g}$ protein. Comparison with the endpoint method of Szutowicz et al. (1984) Anal. Biochem. 138, 86-94)) gave a good correlation $(\mathrm{r}=0.983)$. The reference values for the activity of human platelet monoamine oxidase by the new continuous ABTS method are 25 to $42 \mathrm{U} / \mathrm{g}$ protein $(\overline{\mathrm{x}}=33.2 \mathrm{U} / \mathrm{g}$ protein, $\mathrm{CV}=15.5 \%, \mathrm{n}=67)$. No differences were found between females and males, or between three age groups ranging from 21 to 52 years. The patients with chronic $(n=76)$ or acute $(n=17)$ schizophrenia had significantly lower monoamine oxidase activities compared with normal values $(p<0.005)$, which indicates that platelet monoamine oxidase can be a possible marker for schizophrenic diseases.

\section{Introduction}

The activity of monoamine oxidase (amine: oxygen oxidoreductase (deaminating) (flavin-containing), EC 1.4.3.4) in human platelets has recently been the subject of many studies and a number of reviews in biological psychiatry $(1-3)$. Human platelet monoamine oxidase is exclusively of the B-type and preferentially deaminates $\beta$-phenylethylamine and benzylamine. Study of platelet monoamine oxidase is attractive, because thrombocytes are easy to obtain and they reflect some properties of the central serotonergic system $(1,2)$.

A common problem in the determination of monoamine oxidase and a possible explanation of discrepancies between different studies lies in the diversity of the methods used. The sensitive colorimetric methods for the assay of monoamine oxidase, which measure
$\mathrm{H}_{2} \mathrm{O}_{2}$, use either carcinogenic or very unstable chromogens $(4,5)$.

Here we describe a new and simple continuous monitoring method for the assay of monoamine oxidase based on the oxidation of 2,2'-azino-di(3-ethylbenzthiazoline-6-sulphonate) (ABTS) in the coupled reaction system:

$$
\begin{array}{lcl}
\begin{array}{l}
\mathrm{RCHNH}_{2}+\mathrm{O}_{2} \\
+\mathrm{H}_{2} \mathrm{O}
\end{array} & \stackrel{\text { Monoamine }}{\longrightarrow} & \begin{array}{l}
\mathrm{RCHO}+\mathrm{H}_{2} \mathrm{O}_{2} \\
+\mathrm{NH}_{3}
\end{array} \\
\mathrm{H}_{2} \mathrm{O}_{2}+\mathrm{ABTS}_{\mathrm{red}} \stackrel{\text { Peroxidase }}{\longrightarrow} & \text { ABTS }_{\mathrm{ox}}+2 \mathrm{H}_{2} \mathrm{O}
\end{array}
$$

The absorbance increase due to the formation of oxidized ABTS, recorded every minute at $410 \mathrm{~nm}$, is proportional to monoamine oxidase catalytic activity $(6,7)$. 
Suzutowicz et al. (8) used the same chromogen for an end-point monoamine oxidase assay. The ABTS method, proposed here, based on the measurement of the initial reaction rate, is simpler and faster than the previously described end-point method (8). This continuous monitoring method was applied to platelets and statistically evaluated. Reference values were determined, and the method was applied to platelet samples obtained from schizophrenic patients.

\section{Materials and Methods}

Chemicals

The diammonium salt of 2,2'-azino-di(3-ethylbenzthiazoline-6sulphonate) cryst., was purchased from Boehringer Mannheim, FRG. Horseradish peroxidase, with specific activity $250 \mathrm{kU}$ $\cdot \mathrm{g}^{-1}$, benzylamine hydrochloride, tyramine free base, harmaline hydrochloride, pargiline hydrochloride and all other chemicals of analytical reagent grade were obtained from Sigma Chemical Co. USA.

\section{Biological materials}

The investigations were carried out on human platelets prepared according to Zeller et al. (9). The platelet samples were kept at $-70^{\circ} \mathrm{C}$ before determination of the monoamine oxidase catalytic activity. The monoamine oxidase was quantitatively isolated from platelets according to Summers et al. (10). The obtained platelet homogenate suspension was used for all experiments.

The control group contained 67 apparently healthy persons of both sexes between 21 and 52 years of age. The 93 males and females between 17 and 62 years of age were separated into two subgroups of chronic and acute illness with confirmed diagnosis. The first group consisted of 76 subjects and the second one of 17 patients. No therapy with monoamine oxidase inhibitors was applied.

\section{Reagent solution}

The optimal concentration of each component of the reagent was determined. The reagent had the following composition: $0.5 \mathrm{mmol}$ benzylamine or $1.0 \mathrm{mmol}$ tyramine, $2.0 \mathrm{mmol}$ ABTS, $2000 \mathrm{U}$ peroxidase and $30 \mathrm{mmol} \mathrm{NaN} \mathrm{N}_{3}$ in $1000 \mathrm{ml}$ of $100 \mathrm{mmol} / \mathrm{l}$ TRIS-HCl buffer, $\mathrm{pH}$ 7.6.

\section{Spectrophotometric assay of monoamine oxidase Procedure}

Pipette into the cuvette $1.0 \mathrm{ml}$ of reagent solution and $10 \mu \mathrm{l}$ of platelet homogenate suspension, mix well and equilibrate for 5 minutes at $37^{\circ} \mathrm{C}$. The increase of absorbance at $410 \mathrm{~nm}$ in a $1.0 \mathrm{~cm}$ light path is recorded after 1,2 and 3 minutes immediately following the preincubation. Absorbance changes per minute $\left(\Delta \mathrm{A}_{410 \mathrm{~nm}} / \mathrm{min}\right)$ are calculated.

\section{Calculation}

The monoamine oxidase activity was calculated as $\Delta \mathrm{A}_{410 \mathrm{~nm}} / \mathrm{min}$ $\times 3961$ on the basis of an ABTS molar lineic absorbance of $2550 \mathrm{~m}^{2} / \mathrm{mol}$ (6). Monoamine oxidase activity was expressed as units per gram of protein. Protein was determined according to Lowry et al. (11).

\section{Statistical methods}

Statistical parameters, such as the mean value $(\bar{x})$, standard deviation (SD), coefficient of variation (CV) and Student's ttest were calculated with standard statistical methods. Our method was compared with the end-point method (8) by regression analysis using the method of least squares (12).

\section{Apparatus}

All spectrophotometric measurements were performed with Beckman DU-8 and Gilford Stasar-III spectrophotometers.

\section{Results \\ Continuous monitoring assay of monoamine oxidase}

The new spectrophotometric, continuous monitoring method for determination of monoamine oxidase catalytic activity in tissue, based on oxidation of the chromogen ABTS through the system of coupled reactions catalysed by monoamine oxidase and peroxidase, has already been published (7). To optimise this assay for estimation of platelet monoamine oxidase activity, the conditions characterising this reaction system were studied. The optimal concentrations of benzylamine and tyramine as substrates were determined by varying their concentrations over the ranges $0-1.0 \mathrm{mmol} / \mathrm{l}$. Measurements were made with $78 \mathrm{U} / \mathrm{g}$ protein monoamine oxidase, using a reagent solution containing $2 \mathrm{mmol} / \mathrm{l} \mathrm{ABTS}$ and $2000 \mathrm{U} / 1$ peroxidase in $100 \mathrm{mmol} / \mathrm{l}$ TRIS-HCl buffer, $\mathrm{pH}$ 7.6. All determinations were done in triplicate. The resulting $L i$ neweaver-Burk plots gave $K_{\mathrm{m}}=0.204 \mathrm{mmol} / 1$ for benzylamine and $0.284 \mathrm{mmol} / \mathrm{l}$ for tyramine (fig. 1). The maximum velocity for both substrates was obtained with $2.0 \mathrm{mmol} / \mathrm{l} \mathrm{ABTS}$ and $2000 \mathrm{U} / \mathrm{l}$ peroxidase, using $0.5 \mathrm{mmol} / \mathrm{l}$ benzylamine or $1.0 \mathrm{mmol} / \mathrm{l}$ tyramine in the reaction mixture.

The temperature dependence of monoamine oxidase activity was determined under the established optimal conditions, between $25^{\circ} \mathrm{C}$ and $55^{\circ} \mathrm{C}$, using $58 \mathrm{U} / \mathrm{g}$ protein enzyme activity. Using both substrates, maximum activity was obtained at $37^{\circ} \mathrm{C}$, which was established as the optimal temperature for all further assays (fig. 2).

Platelet monoamine oxidase was characterised as type $B$ with benzylamine as substrate, using two inhibitors harmaline and pargyline. In this experiment, the monoamine oxidase activity was $78 \mathrm{U} / g$. Under the established optimal conditions, using $100 \mu \mathrm{mol} / \mathrm{l} \mathrm{har-}$ maline or $10 \mu \mathrm{mol} / \mathrm{l}$ pargiline, the resulting Lineweaver-Burk plots gave $K_{\mathrm{i}} 24.6 \mu \mathrm{mol} / 1$ and 7.04 $\mu \mathrm{mol} / \mathrm{l}$, respectively (fig. 3 ).

Negative interference by catalase present in the sample was avoided by addition of $30 \mathrm{mmol} / \mathrm{I} \mathrm{NaN}_{3}(13)$. 


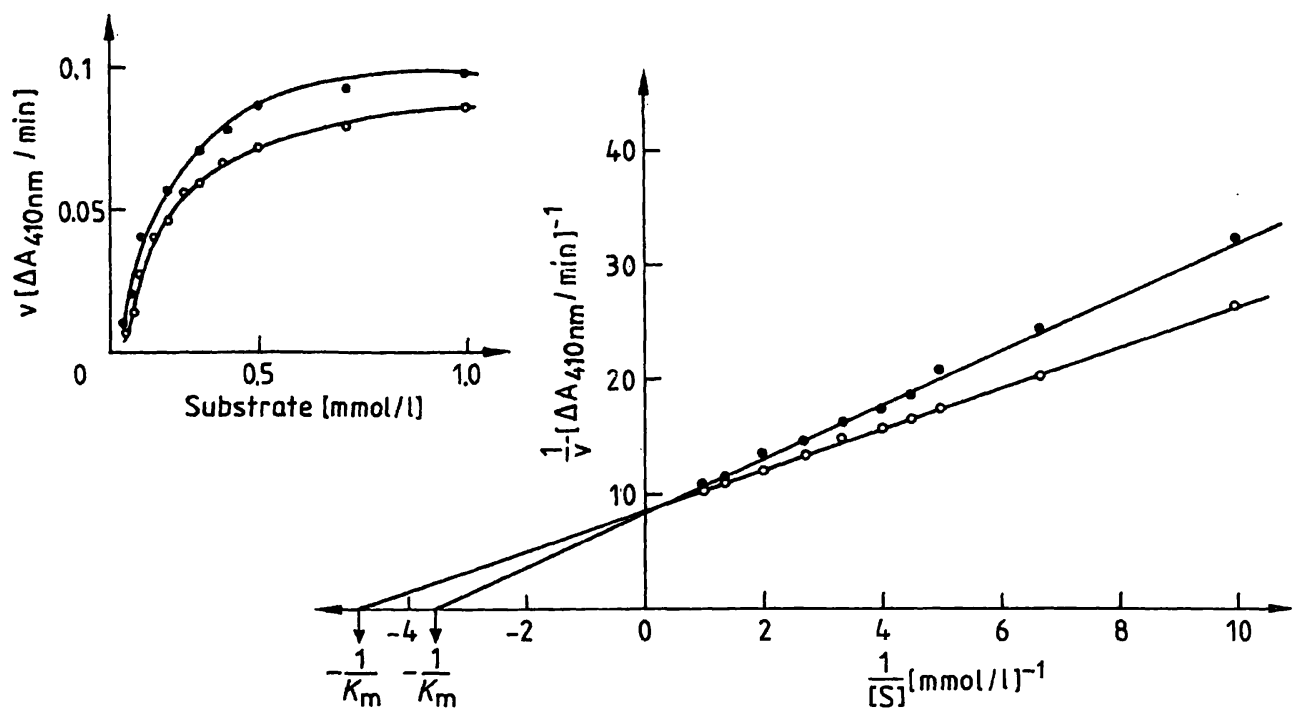

Fig. 1. Lineweaver-Burk plots for benzylamine $\left(0-0, y_{x}=1.767 x+8.625, r=0.999, K_{m}=0.204 \mathrm{mmol} / \mathrm{l}\right)$ and tyramine $(\bullet-0$, $\left.\mathrm{y}_{\mathrm{x}}=2.511 \mathrm{x}+8.803, \mathrm{r}=0.997, K_{\mathrm{m}}=0.284 \mathrm{mmol} / \mathrm{l}\right)$ in $100 \mathrm{mmol} / \mathrm{l}$ TRIS-HCl buffer, $\mathrm{pH}$ 7.6. The Michaelis plots are inset. Conditions: for monoamine oxidase assay see "Procedure".

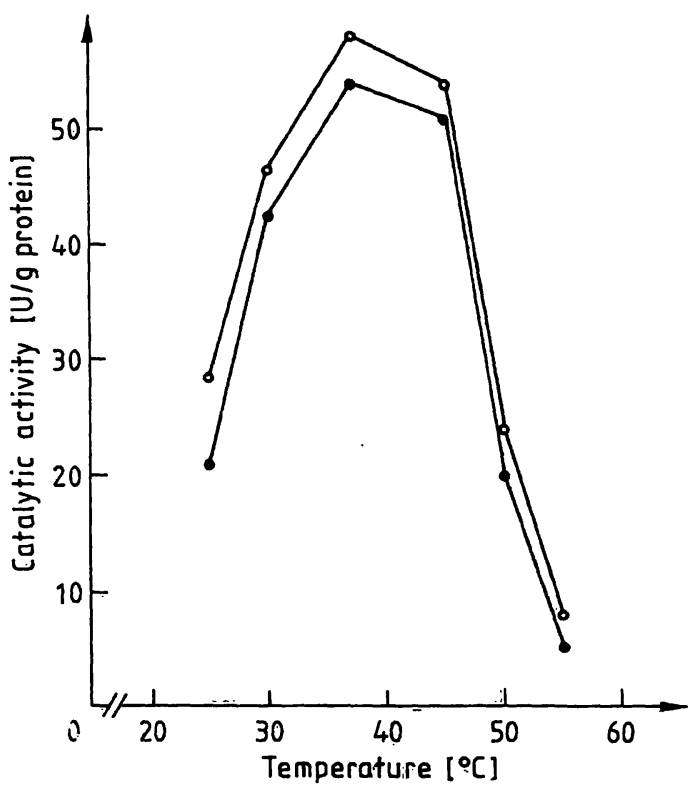

Fig. 2. The effect of temperature on monoamine oxidase activity investigated" with benzylamine $(\mathrm{O}-\mathrm{O})$ and tyramine (०-0) in $100 \mathrm{mmol} / 1$ TRIS-HCl buffer, $\mathrm{pH} 7.6$.

\section{Analytical results}

The linearity of the continuous monitoring ABTS method was examined in the range of 0 to $83 \mathrm{U} / \mathrm{g}$ platelet protein. Each sample was analysed in triplicate. By regression analysis it was found that the Lambert-Beer law was valid up to $83 \mathrm{U} / \mathrm{g}$ protein $(y=91.625 x-1.510, r=0.998, S y, x=2.125)$. The lowest catalytic activity of monoamine oxidase that could still be assayed with good precision (CV $=7.0 \%$ ) was $6.9 \mathrm{U} / \mathrm{g}$ protein.

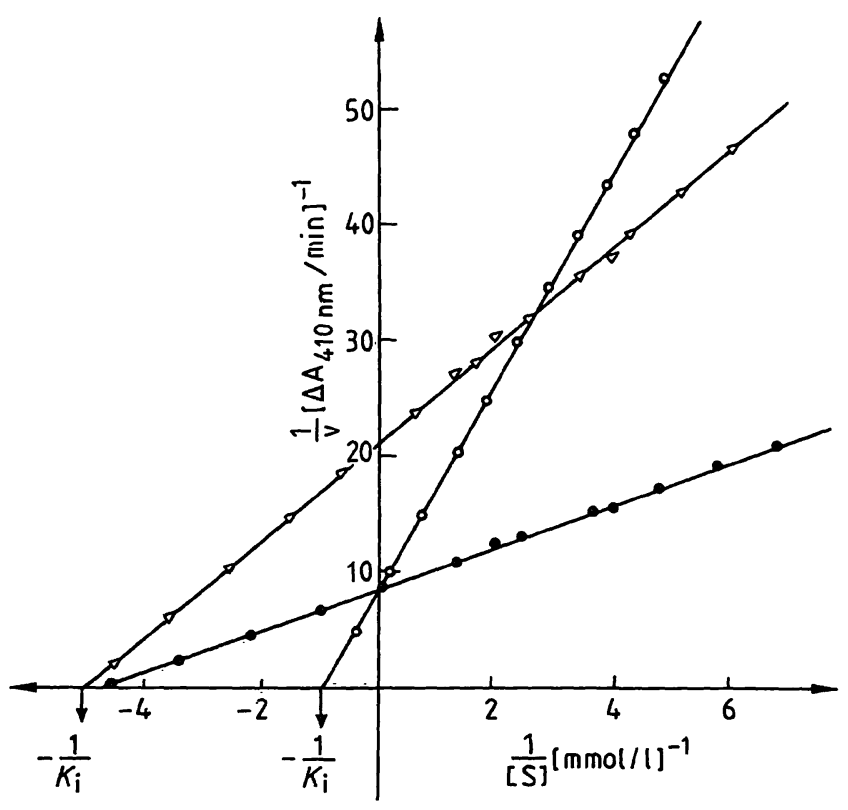

Fig. 3. Double reciprocal plots for benzylamine oxidation by human platelet monoamine oxidase in the presence of $100 \mu \mathrm{mol} / 1$ harmaline $(0-0), 10 \mu \mathrm{mol} / 1$ pargyline $(\Delta-\Delta)$, and without inhibitor $(0-0)$. Conditions: for monoamine oxidase assay see "Procedure".

The precision of the ABTS method was examined with three different samples, containing low, normal and high monoamine oxidase activity, using benzylamine and tyramine as substrates. All determinations were repeated 10 times and calculated mean values. standard deviations and coefficients of variation are shown in table 1.

The accuracy of the proposed continuous monitoring ABTS method was evaluated by comparison with the end-point ABTS method originally established by 
Tab. 1. Precision of the continuous monitoring ABTS method $(n=10)$ investigated by use of two substrates

\begin{tabular}{llll}
\hline Substrate & $\begin{array}{l}\overline{\mathrm{x}} \\
(\mathrm{U} / \mathrm{g})\end{array}$ & $\begin{array}{l}\text { SD } \\
(\mathrm{U} / \mathrm{g})\end{array}$ & $\begin{array}{l}\text { CV } \\
(\%)\end{array}$ \\
\hline Benzylamine & 11.7 & 0.81 & 6.9 \\
& 33.9 & 1.38 & 4.1 \\
& 72.4 & 1.80 & 2.5 \\
Tyramine & 8.9 & 1.10 & 12.1 \\
& 28.8 & 1.04 & 3.4 \\
& 60.5 & 1.90 & 3.1 \\
\hline
\end{tabular}

Szutowicz et al. (8). Both methods were applied to 60 platelet samples. Monoamine oxidase activity ranged from 15 to $97 \mathrm{U} / \mathrm{g}$ protein. An acceptable correlation $(y=0.897 x+0.920, r=0.983, S y, x=3.423)$ was obtained (fig. 4). No significant difference up to $50 \mathrm{U} / \mathrm{g}$ protein was obtained ( $p>0.01$ ).

When the platelet monoamine oxidase activity was greater than $60 \mathrm{U} / \mathrm{g}$ protein, the continuous monitoring ABTS method gave results that were elevated by about $10 \%$.

Monoamine oxidase activity in normal and pathological samples

Reference values for human platelet monoamine oxidase were determined using the new continuous monitoring ABTS method on 67 healthy persons of both sexes between 18 and 57 years of age. The statistical parameters of the reference group were: $\overline{\mathrm{x}}=33.2 \mathrm{U} / \mathrm{g}$ protein, $\mathrm{SD}=5.2 \mathrm{U} / \mathrm{g}$ protein, $\mathrm{CV}=15.5 \%$. The lowest value in the reference group was $25 \mathrm{U} / \mathrm{g}$ protein and the highest value was $42 \mathrm{U} / \mathrm{g}$ protein. In view of the number of subjects in the reference group we propose that these are the limits of the "normal" range. The platelet monoamine oxidase activity does not depend on sex or age.

Using the new continuous monitoring ABTS method, platelet monoamine oxidase activities were determined in samples obtained from 76 patients with chronic schizophrenia and 17 patients in acute phase (fig. 5).

Both schizophrenic patient groups, chronic as well as acute, had significantly lower platelet monoamine oxidase activity $(p<0.005)$ than control group. The mean value of platelet monoamine oxidase activity in the group of chronic patients was $29.2 \mathrm{U} / \mathrm{g}$ protein. In the group with acute disease the mean value of monoamine oxidase activity was $24.2 \mathrm{U} / \mathrm{g}$ protein. This activity is significantly lower than in the control group ( $p<0.001$ ). However, no statistically significant difference between chronic and acute patient groups was found $(p>0.05)$.

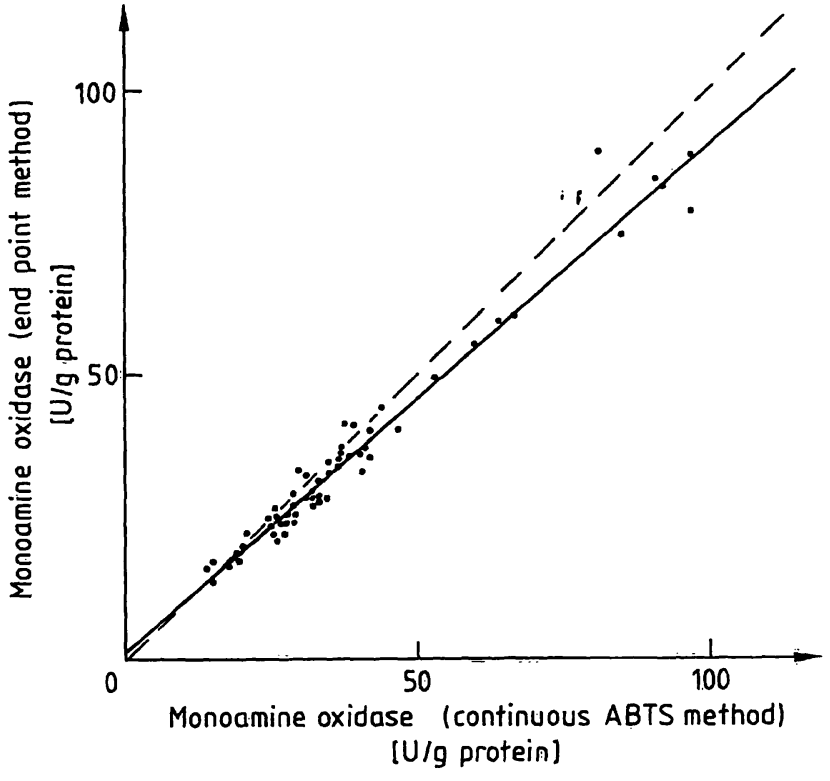

Fig. 4. Correlation of results obtained by continuous monitoring ABTS method ( $x$ ) and end-point ABTS method (y) in 60 different platelet samples: $y_{x}=0.920+0.897 x$, $\mathrm{r}=0.983, \mathrm{Sy}, \mathrm{x}=3.423$.

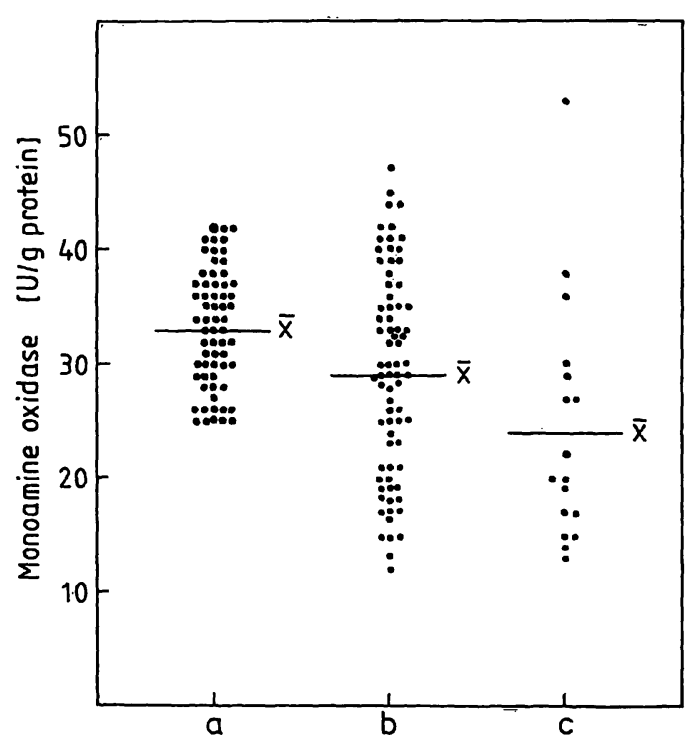

Fig. 5. Monoamine oxidase activities determined in platelets of 67 healthy persons (a), 76 chronic schizophrenic patients (b) and 17 patients with acute disease (c).

\section{Discussion}

Monoamine oxidase is an intracellular enzyme, principally found in all tissues and predominantly bound to the inner mitochondrial membrane $(14,15)$. Many methods for determination of monoamine oxidase activity have been developed. Mostly they are timeconsuming, use radio-active labelled substrates, carcinogenic or unstable chromogens and are not practicable in routine work. For these reasons we propose here a new spectrophotometric assay based on measurement of the initial oxidation' rate of chromogen ABTS. For the continuous monitoring ABTS method 
benzylamine and tyramine were used as substrates. The proposed continuous assay of monoamine oxidase activity is simple, fast and takes advantages of the high aqueous solubility and molar lineic absorbance of $\operatorname{ABTS}(6,7,13)$. The rate of change in the absorbance of the chromogen can be measured in a low-cost visible range photometer. The investigation presented here showed that the ABTS method is sensitive, linear up to $83 \mathrm{U} / \mathrm{g}$ platelet protein and precise (CV below $7.0 \%$ for substrate benzylamine). Good correlation was obtained with the end-point ABTS method $(r=0.983)$.

Many studies have been published on the reference values of platelet monoamine oxidase activity. The diversity of the methods make any comparison very difficult. In any case we found no influence of age and sex on monoamine oxidase activity, which is in agreement with many other authors $(9,16,17)$. However, Summers et al. (18) found statistically significant differences between sexes, with a similar turnover number for monoamine oxidase activity in platelets.

Platelet monoamine oxidase in psychiatric populations has been studied by many investigators. They found that monoamine oxidase activity markedly depends upon the psychiatric state, as well as genetic and hormonal factors. Nies et al. (19) and Murphy \&

\section{References}

1. Fowler, C. J., Tipton, K. F., MacKay, A. V. P. \& Youdim, M. B. (1982) Neuroscience 7, 1577-1594.

2. Oreland, R. \& Shaskan, E. G. (1983) Trends Pharmacol. Sci. 4, 339-341.

3. Sandler, M., Raveley, M. A. \& Glover, V. (1981) J. Clin. Pathol. 34, 292-302.

4. McEwen, C. M. Jr. (1956) J. Biol. Chem. 240, 2003-2010.

5. Kochli, H. \& von Wartburg, J. P. (1978) Anal. Biochem. $84,127-135$.

6. Majkić, N. \& Berkeš, I. (1977) Clin. Chim. Acta 80, 121 131.

7. Ivanović, D. I. \& Majkić-Singh, N. (1986) Fresenius Z. Anal. Chem. 324, 307.

8. Szutowicz, A., Kobes, R. D. \& Orsulak, P. J. (1984) Anal. Biochem. 138, 86-94.

9. Zeller, E. A., Huprikar, S. V., Gibbons, R. D. \& Millar, E. (1984) Clin. Chim. Acta 137, 123-129.

10: Summers, K. M., Brown, G., K., Graig, I. W., Littlewood, J., Peatfield, R., Glover, V., Rose, F. C. \& Sandler, M. (1982) Clin. Chim. Acta 121, 139-146.

11. Lowry, O. H., Rosebrough, N. J., Farr, A. L. \& Randall, R. J. (1951) J. Biol. Chem. 193, 265-275.

12. Bauer, E. L. (1971) Statistical Methods for Chemists, Academic Press, pp. $71-93$.

13. Majkić-Singh, N., Conteh, B., Stojanov, M. \& Berkeš, I. (1983) Enzyme 29, 120-125.

14. Blaschko; H., Richter, D. \& Schlossmann, M. (1937) Biochem. J. 31, 2187-2196.
Wyatt (20), using tryptamine as well as other substrates, reported that platelet monoamine oxidase activity was significantly lower in chronic schizophrenic patients than in control subjects. Meltzner \& Stahl (21) pointed out the platelet monoamine oxidase activity was lower in patients with acute schizophrenia than in the control subjects, but only when tyramine was used as substrate. Friedman et al. (22) found no difference in monoamine oxidase activity between patients and normal control subjects, using tryptamine as substrate. In contrast, Bailey et al. (23), Groshong et al. (24) and Schildkraut et al. (25) did not find a lower platelet monoamine oxidase activity in schizophrenic patients using different substrates. Other authors, such as Balmaker et al. (17), reported slightly higher monoamine oxidase activity in schizophrenic patients. As shown in figure 5, platelet monoamine oxidase activity was significantly lower in chronic as well as acute schizophrenic patients than in the control group. Nevertheless, wide range of the results (from 12 to $52 \mathrm{U} / \mathrm{g}$ protein) indicate that many factors, hormonal, dietary or genetic may influence the platelet monoamine oxidase level $(19,20,26)$. However, the presented data suggest the need for further clinical investigation of the continuous monitoring ABTS method, as a convenient laboratory test capable of producing comparable interlaboratory results.

15. Youdim, M. B. H. \& Holzbauer, M. (1976) J. Neurol. Transmission 38, 193-229.

16. Domino, E. F. \& Khanna, S. S. (1976) Am. J. Psychiatry $133,323-326$.

17. Belmaker, R. H., Ebbesen, K., Ebstein. R. \& Rimon, R. (1976) Brit. J. Psychiat. 129, 227-232.

18. Summers, K. M., Andrew, B., Gillespie, C., Watt, D. C. \& Craig, I. W. (1985) Clin. Chim. Acta 152, 289-296.

19. Nies, A., Robinson, D. S. \& Harris, L. S. (1974) In: Advances in Biochemical Pharmacology (Usdin, E., ed.) Raven Press (New York) Vol. 12, pp. 59-70.

20. Murphy, D. L. \& Wyatt, R. J. (1972) Nature 238, 225226.

21. Meltzer, H. Y. \& Stahl, S. M. (1974) Res. Commun. Chem. Pathol. Pharmacol. 7, 419-431.

22. Friedman, E., Shopsin, B. \& Sathanthan, G. (1974) Am. J. Psychiatry $131,1392-1394$.

23. Bailey, A. R., Crow, T. J. \& Johnstone, E. C. (1975) Br. J. Clin. Pharmacol. 2, 380-386.

24. Groshong, R. \& Baldessarini, R. J. (1978) Arch. Gen. Psychiatry 35, 1198-1205.

25. Schildkraut, J. J., Herzog, S. M. \& Orsulak, P. J. (1976) Am. J. Psychiatry 133, 438-440.

26. Youdim, M. B. H.. Holzbauer, M. \& Woods, H. F. (1974) In: Advences in Biochemical Pharmacology (Usdin, E., ed.) Raven Press (New York) Vol. 12, pp. 11-28.

Prof. Dr N. Majkić-Singh

Department of Biochemistry

Faculty of Pharmacy

Dr Subotica 8, P. O. Box 146

YU-I1000 Belgrado 


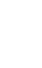

